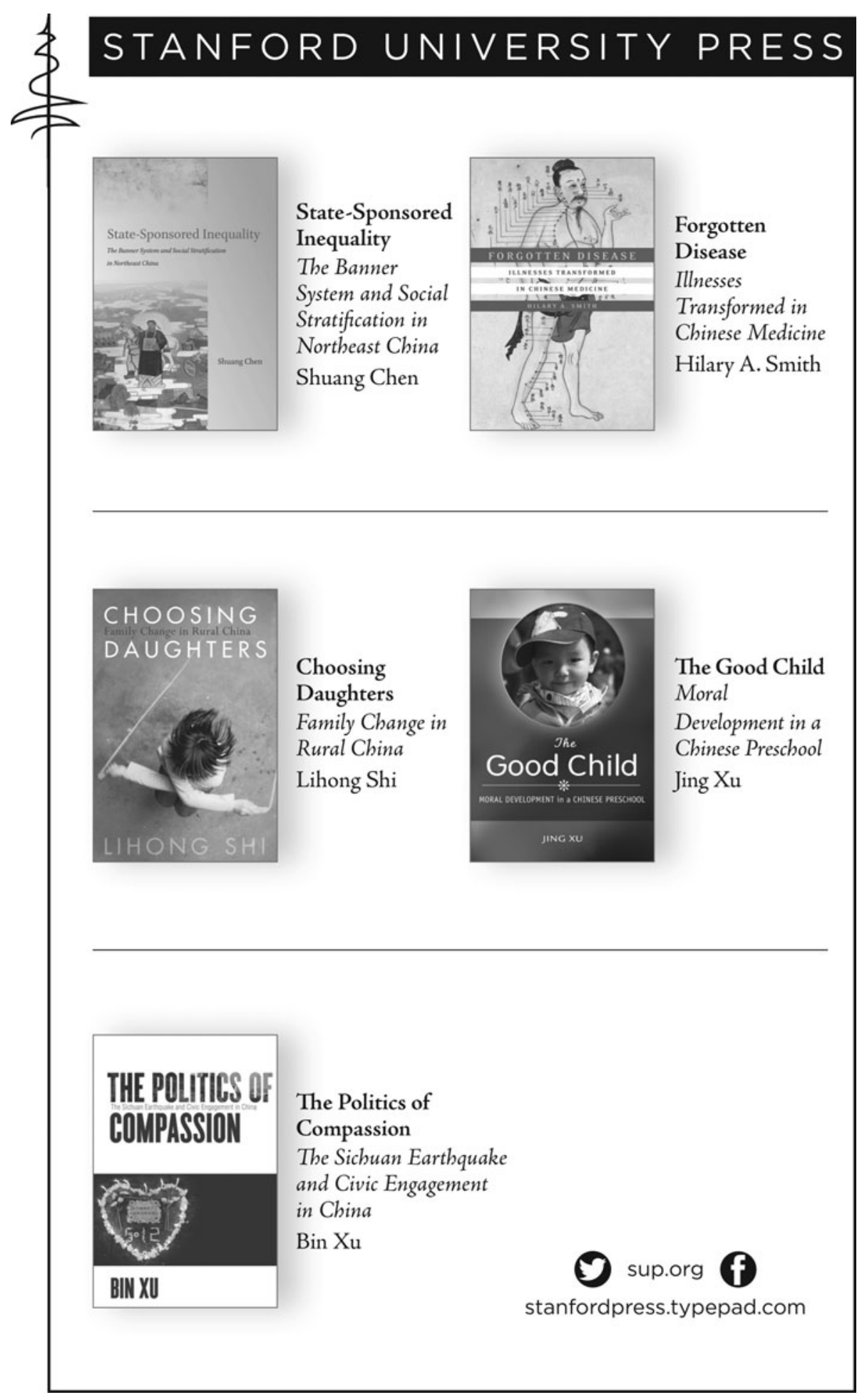




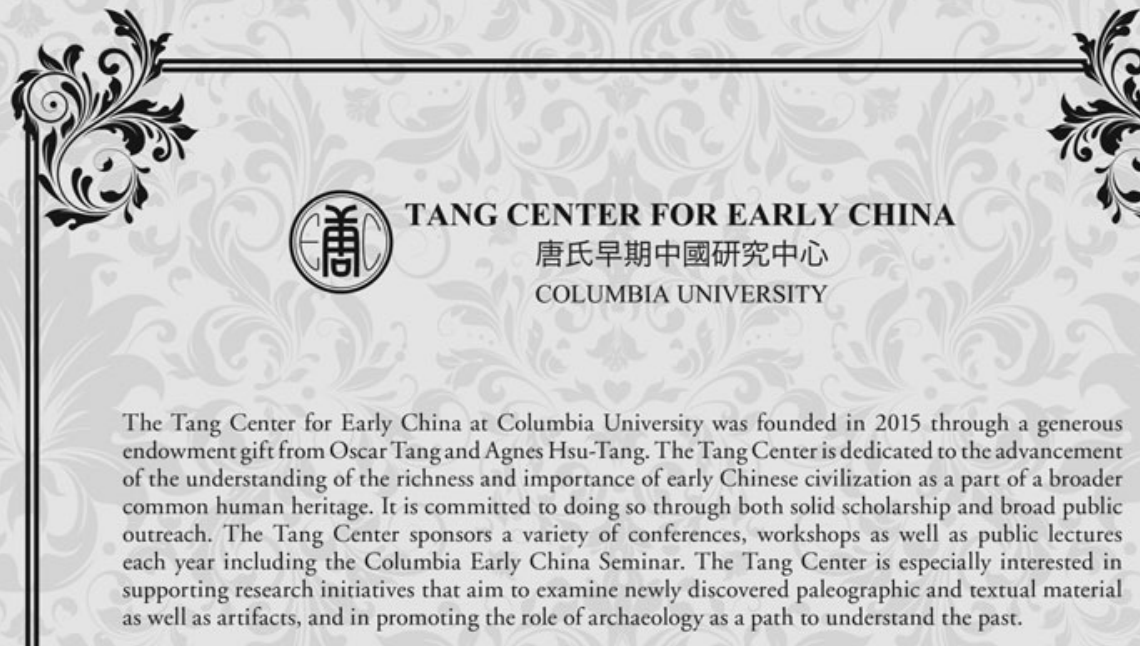

\title{
Call for Manuscripts
}

\section{Tang Center Series in Early China}

Sponsored by the Tang Center and to be published by Columbia University Press, the "Tang Center Series in Early China" includes new studies that make major contributions to our understanding of early Chinese civilization or that which break new theoretical or methodological grounds in Early China studies. The series is especially interested in publishing works that analyze newly discovered paleographic and manuscript materials as well as archaeological data. Disciplinary focuses of the series are history, archaeology, art history, anthropology, literature, philosophy, and the history of sciences and technology. The series spans from the Neolithic period to the end of the Han Dynasty (AD 220), or to the end of the Tang Dynasty (AD 907) for titles in archaeology. All submissions are subject to peer reviews and editorial evaluation. For more information, please see http://tangcenter-columbia. org/publications/. Interested authors should submit a book proposal (maximum 25 manuscript pages), accompanied by CV, to: info@tangcenter-columbia.org, or by mail to: 509 Kent Hall, 1140 Amsterdam Avenue, MC 3907, Columbia University, New York, NY 10027.

\section{Call for Applications}

The Tang Post-Doctoral Research Award in Early China Studies

The Tang Center for Early China offers one Post-Doctoral Research Award in the amount of $\$ 15,000$ each year in recognition of outstanding research projects in early Chinese civilization or in archaeology.

\section{The Tang Visiting Scholar's Fellowship}

The Tang Center offers Visiting Scholar's Fellowship each year to one scholar for an in-residence research period of 10 months at Columbia University, or to two scholars for a period of 5 months each, depending on the need of the proposed projects. The applicant must be non-US based.

\begin{abstract}
Workshop and Conference Grants
The Tang Center offers grants in the amount of $\$ 13,000$ each to up to two workshop and/or conference proposals each academic year, depending on the scale. Each workshop or conference should have an identified central problem or theme on which the papers will focus. Alternatively, the workshop/ conference can be centered on a newly discovered corpus of materials or manuscripts, or on an important archaeological site, or a region.
\end{abstract}

Application deadline, November 30 , for all programs.

For more information, please visit our website www.tangcenter-columbia.org. Questions directed to: info@tangcenter-columbia.org; or by phone: 212.854.5546. 


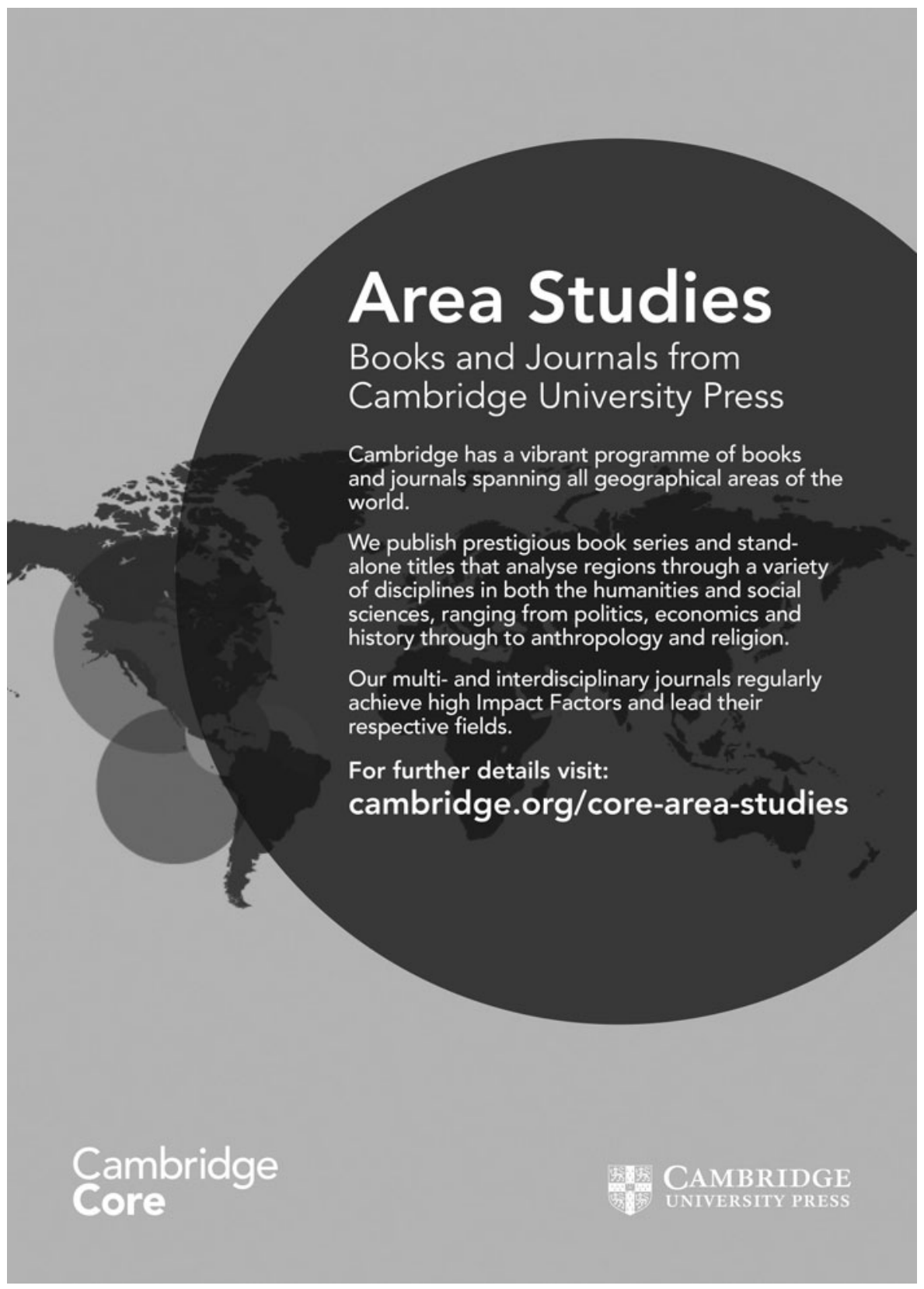




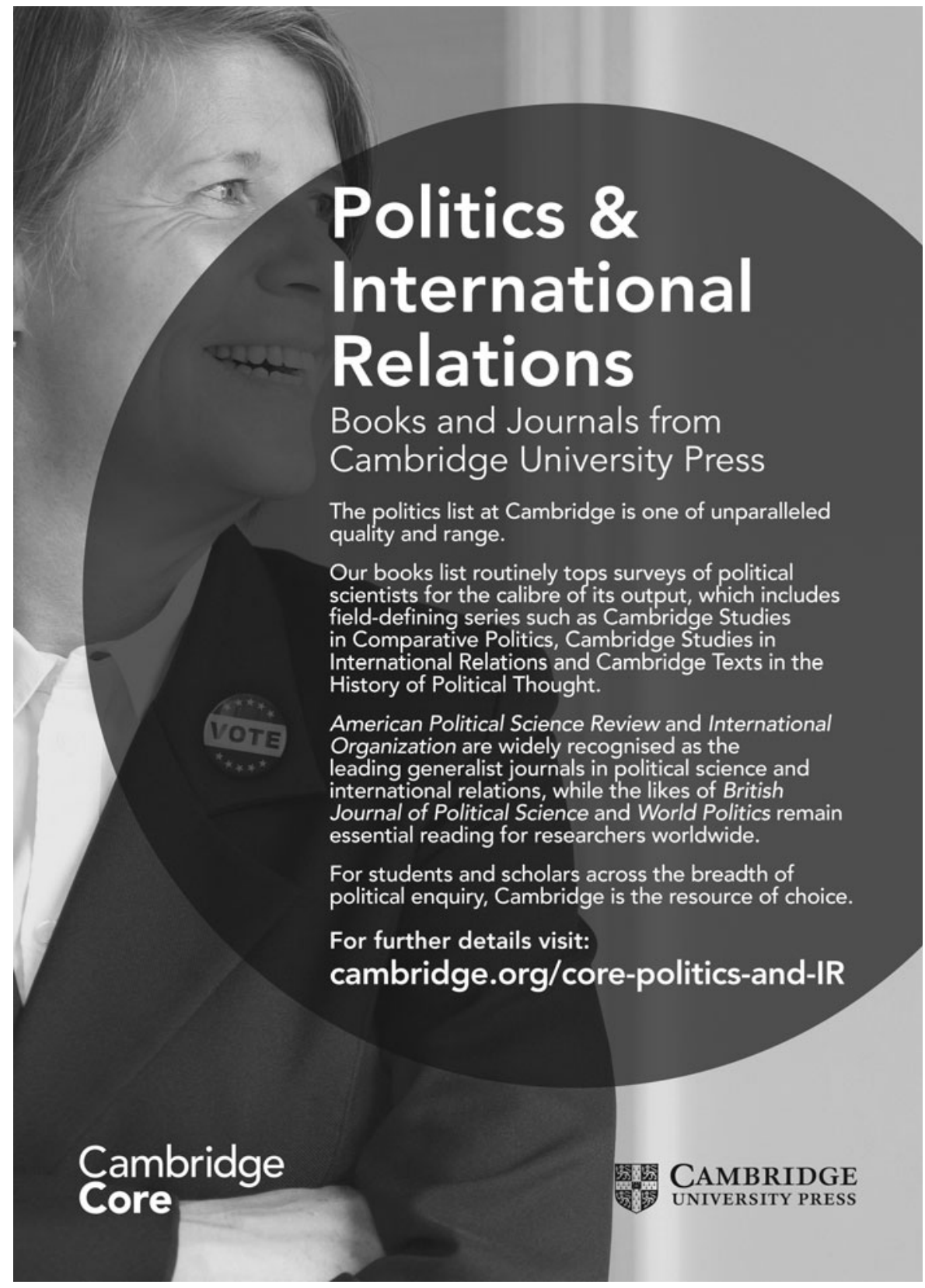




\section{Instructions for Contributors}

The China Quarterly welcomes the submission of manuscripts from scholars, including postgraduate students, on all aspects of contemporary China, including Taiwan, Hong Kong, Macau and Tibet. Submissions in the fields of religion, media, literature, or on China prior to 1978 , will be considered if they engage with issues of wider significance in contemporary China.

The China Quarterly will consider two main types of submissions: regular articles (up to 9,000 words, including footnotes): in-depth and theoretical pieces which should present original research in combination with analytical argument; Research reports (up to 4,000 words, including footnotes): shorter pieces based on primary research and empirical evidence. We will not consider manuscripts that are under consideration elsewhere, or that have been published in any form in any language.

Article manuscripts should be submitted through the ScholarOne online submission and peer review system (http://mc.manuscriptcentral.com/cqy). If you experience technical difficulties, please contact the Editorial Office at chinaq@soas.ac.uk. An abstract of 100-150 words, some keywords and a bibliography should also be provided.

All submissions should conform to the styling of The China Quarterly.

\section{Style}

\section{Romanization and Chinese characters}

Use pinyin without tone/diacritical marks, except for Chiang Kai-shek, Sun Yat-sen, Taipei, Kuomintang, and names of people living outside mainland China. Give Chinese characters on the first occurrence of each Romanization.

Chinese characters are incorporated into article texts (ie. English (pinyin, characters)) so authors must provide Chinese characters for all Chinese used in the main text (not footnotes) on first appearance, including pinyin phrases, people's names and geographical locations.

\section{Numbers}

One to ten spelled out, 11 or more in figures; per cent in text, but \% in footnotes. Dates: 2 March 1993. Page references: $324-26$ but 324-336.

\section{References in footnotes}

Books, chapters and articles should be shortened to the author-date-page format as follows:

Smith 2010, 15.

Smith and Wang 2011, 55-57.

\section{Bibliography}

All bibliographical references should be included at the end of the article in alphabetical order. Examples:

O'Brien, Kevin, and Lianjiang Li. 2006. Rightful Resistance in the Chinese Countryside. New York: Cambridge University Press.

Chen, Peiai. 2008. Zhongwai guanggao shi (A History of Advertising in China and Beyond). Beijing: Zhongguo yujia chubanshe.

Perry, Elizabeth, J. 2011. "From mass campaigns to managed campaigns: 'constructing a new socialist countryside'." In Sebastian Heilmann and Elizabeth J. Perry (eds.), Mao's Invisible Hand: The Political Foundations of Adaptive Governance in China. Cambridge, MA: Harvard University Press, 30-61.

Kong, Baohua. 2011. "Gongmin canyu he gongmin yishi” (Civic participation and civic consciousness). In Zhang Miaoqing et al. (eds.), Aomen tequ xinxiang: shi nian fazhan yu bianhua (The New Face of Macao SAR: Ten Years of Development and Changes). Hong Kong: Zhongwen daxue Xianggang Yatai yanjiusuo, 339-362.

Jung, Chulho, Kerry Krutilla and Roy Boyd. 1996. "Incentives for advanced pollution abatement technology at the industry level: an evaluation of policy alternatives." Journal of Environmental Economics and Management 30 (1), 95-111.

Liu, Weikeng. 2006. "Lingnan shezhi zuizao de liu xian zhiyi - Sihui" (Sihui: one of the six counties set up the earliest in Lingnan's history). Lingnan wenshi 3, 12-14.

A more detailed style sheet is available on request and online at journals.cambridge.org/CQY

\section{Copyright}

It is a condition of publication in the Journal that authors assign copyright to SOAS University of London. This ensures that requests from third parties to reproduce articles are handled efficiently and consistently and will also allow the article to be as widely disseminated as possible. In assigning copyright, authors may use their own material in other publications provided that the Journal is acknowledged as the original place of publication, and Cambridge University Press is notified in writing and in advance.

\section{CAMBRIDGE UNIVERSITY PRESS}

University Printing House, Cambridge CB2 8BS, United Kingdom

1 Liberty Plaza, Floor 20, New York, NY 10006, USA

477 Williamstown Road, Port Melbourne, VIC 3207, Australia

Ruiz de Alarcón 13, 28014 Madrid, Spain 


\section{Contents}

565 Foreword by the Editor

Tim Pringle

\section{Special section on Central-Local Relations and Environmental Governance in China}

567 Introduction. Central-Local Relations: Recentralization and Environmental Governance in China

Genia Kostka and Jonas Nahm

583 Centralizing Trends and Pollution Law Enforcement in China Benjamin van Rooij, Qiaoqiao Zhu, Li Na and Wang Qiliang

607 Neither Centre nor Local: Community-Driven Experimentalist Governance in China

Kyoung Shin

634 Understanding Blame Politics in China's Decentralized System of Environmental Governance: Actors, Strategies and Context Ran Ran

662 China's War on Air Pollution: Can Existing Governance Structures Support New Ambitions?

Christine Wong and Valerie J. Karplus

685 Central Protectionism in China: The "Central SOE Problem" in

Environmental Governance

Sarah Eaton and Genia Kostka

705 Exploiting the Implementation Gap: Policy Divergence and Industrial Upgrading in China's Wind and Solar Sectors Jonas Nahm

728 Local Governance Pathways to Decarbonization in China and India Bruce Gilley

749 Implementation of Pollution Control Targets in China: Has a Centralized Enforcement Approach Worked?

Xuehua Zhang

\section{State of the Field}

775 The Ecology of Chinese Academia: A Third-Eye Perspective Jinba Tenzin

\section{Duihua Academic Exchange}

797 Missing Girls or Hidden Girls? A Comment on Shi and Kennedy's "Delayed Registration and Identifying the 'Missing Girls' in China" Yong Cai

804 Missing Girls, Indirect Measures and Critical Assumptions: A Response to Yong Cai's Comments

Yaojiang Shi and John James Kennedy

\section{Book Reviews}

837 Books Received

839 Notes on Contributors

\section{Cambridge Core}

For further information about this journal please go to the journal web site at:

cambridge.org/cqy

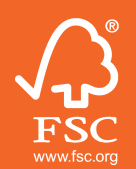

MIX Paper from
responsible sources ANIBRIDGE FSC ${ }^{\circ}$ C007785 UNIVERSITY PRESS 